\title{
Vivendo estados alterados - a consciência como uma narrativa em aberto
}

\author{
Antonio José de Meneses Gonçalves ${ }^{1}$
}

Resumo: Estudos cognitivos indicam que o ordenamento do real se dá como uma experiência narrativa que emerge em nossas redes neurais. Desse ponto de vista, estados alterados - sejam associados a drogas ou a patologias psíquicas - podem ser vistos como narrativas alternativas à da normalidade.

Palavras-chave: cognição; loucura; drogas; consciência

Title: Living altered states - consciousness as an open narrative Abstract: Cognitive studies indicate that organization of reality comes as a narrative that emerges in our neural networks. From this point of view, altered states - possibly associated with drugs or psychological diseases - can be viewed as alternative narratives.

keywords: cognition; madness; drugs; consciousness

1 Doutor em História das Ciências e das Técnicas e Epistemologia/UFRJ e Doutor em Engenharia Civil, COPPE-UFRJ. 


\section{Introdução}

As últimas duas décadas foram bastante férteis para o estudo da mente. Considerando a convergência interdisciplinar que caracteriza as pesquisas neste início de século, podemos afirmar que somos, sob o ponto de vista cognitivo, animais com peculiaridades que nos diferenciaram ao permitirem a emergência do que chamamos razão. Estudos em inteligência artificial, psicologia cognitiva e neurociências sugerem que nossa venerada racionalidade é derivada de mecanismos básicos de simulação sensório-motora. Nesse enfoque, nossa concepção de mundo e de nós mesmos é dialeticamente construída e mantida em narrativas que recontamos incessantemente. Um entrelaçamento de narrativas dá ao mundo inteligibilidade e a nós, identidade. Nosso eu pode ser visto como nossa narrativa mais íntima, que mantemos com inesgotável dedicação, sem prestarmos maior atenção a isso.

A neuropsicóloga Angela Bruzzo e o neurocientista Ram Vimal enfatizam a condição paradoxal na qual o eu e o outro, observador e observado, são inseparáveis. "O self guarda essa qualidade paradoxal porque a autenticidade de uma identidade fixa, sua solidez repousa precisamente em sua falsidade subjacente, ou seja, em sua abertura ou fluidez estrutural." (BRUZZO e VIMAL, 2007, p.558). Só existimos enquanto permanência porque nos modificamos, paradoxo que nos remete às primeiras questões da filosofia na Grécia Antiga. Estudos cognitivos contemporâneos indicam que o ordenamento do devir se dá em narrativas. Conforme o neurocientista António Damásio, "Você 
existe como um ser mental quando histórias primordiais estão sendo contadas, e só então; contanto que histórias primordiais estejam sendo contadas, e só com essa condição. Você é a música enquanto ela dura." (DAMÁSIO, 2000, p.246).

Emergentes em um processo dinâmico, auto-organizado para o ordenamento do mundo e de si mesmo, vivemos em estados alterados por natureza. Nestes termos, poderíamos considerar legítimos os "estados alterados da consciência" sob o efeito de drogas psicoativas?

\section{Uma aventura no devir}

Pesquisadores contemporâneos sugerem que a racionalidade humana é emergente da interação entre os indivíduos e o ambiente, e admitem implicações dessa ideia não apenas na forma como vemos a inteligência biológica e construímos sistemas artificiais, mas também na forma como encaramos nós mesmos e o mundo a nossa volta. Hauser (2008), por exemplo, sugere que o estudo de animais está começando a ter um papel decisivo, justificado não mais por buscarmos limitações na cognição destes, mas por começarmos a vêlos como formas alternativas de cognição e "pensamento". Questões como "os animais são inteligentes?" ou "os animais pensam?" não seriam boas perguntas. Cada espécie seria inteligente à sua maneira, na forma como lida com o ambiente. Até mesmo as plantas, de certa forma, seriam inteligentes: apreendem o ambiente a sua volta e se conformam a ele, buscando um melhor futuro. Inteligentes e melhor seriam sempre relativos.

Abordagens transdisciplinares do mental indicam a origem sensório-motora de nossas habilidades cognitivas de alto nível, como a criação e manipulação de conceitos. É reconhecido que a criação de modelos abstratos complexos se apoia em processos naturais auto- 
organizáveis voltados para a antecipação e alimentados pela história experiencial tecida em nossa memória. Nos termos de Rom Harré e Grant Gillett, "Cada indivíduo possui uma organização única desses construtos, e eles variam em sua capacidade de modificação à luz da nova experiência e de acordo com a forma como são aplicados aos objetos, incluindo este próprio sujeito ativo." (HARRÉ e GILLETT, 1999, p.118). Esta "constelação cognitiva" definiria o indivíduo. Nesse ponto de vista, a construção de nossa racionalidade segue um caminho de forma alguma a nós predestinado, revelando-se claro seu caráter contingente. A razão, suas causas e efeitos, seus sujeitos e objetos em suas diversas versões, estaria imbricada com nossa experiência corporal de forma histórica e culturalmente compartilhada.

O cientista cognitivo Giovanni Pezzulo vê a mente como um dispositivo cuja principal função é se ajustar ao futuro, e representações antecipatórias seriam os meios para tal: "graças à antecipação, as ações podem ser selecionadas pela expectativa de serem bem sucedidas, o que permite coordenação com o futuro" (PEZZULO, 2008, p.216). Desenvolvemos mecanismos para lidar com o futuro, os quais podem ser descritos como formas de simulação da realidade externa que dão origem à representação mental. Podemos encarar nossa existência como a aventura de um organismo dotado da faculdade de auto-organização atuando em um mundo em devir. Em busca de antecipação, nos apoiamos em uma narrativa histórica possibilitada pela memória. Henri Atlan, em 1979, antecipou o que defendem pesquisadores neste início de século: o caráter autoorganizante de nosso aparelho cognitivo movido pelo desejo de antecipação, pelo "querer inconsciente auto-organizador do futuro", seria a base da consciência.

\section{Uma narrativa em aberto}


Pesquisas ao fim do século $X X$ conceituam o self em termos de um espaço dinâmico onde o eu se posiciona, podendo flutuar dentre posições diferentes e até mesmo opostas, associadas a diferentes vozes que interagem em uma história. O resultado é um self complexo e narrativamente estruturado, onde as diferentes posições representariam diferentes pontos de ancoragem. "O self pode ser reformulado como o self narrativo, o que reflete a natureza incorporada e imaginativa da mente humana, e suas ações, pensamentos e sentimentos entendidos como movimento através do espaço e do tempo." (HERMANS e outros, 1992, p.27). Mesmo quando externamente em silêncio, nos achamos conversando internamente com nossos críticos, familiares, nossa consciência, nossos deuses, ou nosso reflexo no espelho, "o self está embutido em um contexto histórico com profundas implicações tanto para a forma como para o conteúdo das narrativas e dos processos dialógicos" (HERMANS e outros, 1992, p.29).

Damásio associa diretamente a consciência à capacidade narrativa, considerando que a consciência se estabelece quando os cérebros adquirem o poder de contar uma "história sem palavras": "a história de que existe vida pulsando incessantemente em um organismo, e que os estados do organismo vivo (...) estão continuamente sendo alterados por encontros com objetos ou eventos em seu meio ou também por pensamentos e ajustes do processo da vida." (DAMÁSIO, 2000, p.51). A intencionalidade que marca o mental estaria associada à capacidade narrativa. "A história encerrada nas imagens da consciência central não é contada por um homúnculo esperto. Tampouco é contada pelo indivíduo considerado como um self, pois o self central só nasce quando a história é contada, dentro da própria história." (DAMÁSIO, 2000, p.246). Nestes termos podemos afirmar que não somos o sujeito que conta ou para quem é contada a 
história, somos a história. Constatação que traz inevitável perplexidade para o senso comum antropocêntrico e transcendental, perplexidade expressa por Damásio: "o espantoso é que a entidade conhecível do captor acaba de ser criada na narrativa do processo de captação." (DAMÁSIO, 2000, p.221)

\section{Incessante construção do eu}

Mas quem, ou o que, é esse ser que se aventura no futuro construindo incessantes antecipações apoiado em uma memória flexível e criativa? Conforme a visão que se consolida neste início de século, não existe um ser, mas um sendo. O eu é visto não como uma substância ou uma função, mas como uma experiência narrativa que emerge em "nossas" redes neurais. Bruzzo e Vimal trabalham com o conceito de metaestabilidade, propondo que fases da formação do eu podem ser comparadas a estados possíveis de um sistema autoorganizante, "cada fase representa um espaço de fase no qual certos processos de desenvolvimento formam poderosos estados atratores" (BRUZZO e VIMAL, 2007, p.550). Internamente, a tríade experiência subjetiva - sujeito - objeto seria uma só atividade em uma rede neural, entretanto, quando projetadas para fora, aparecem distintas, tendo o sujeito como referência. $O$ eu seria a experiência subjetiva deste ponto de referência, o sujeito, "o self parece ser constituído por uma coleção de imagens transientes, um self construído, uma condensação de experiências relacionadas." (BRUZZO e VIMAL, 2007, p.551)

A rigor, não haveria uma memória do eu, mas um eu da memória. Existimos apenas como relação, nos reconhecemos continuamente enquanto nos transformamos. Conforme Damásio, "vislumbramos um processo incessante de construção e demolição, e 
percebemos que a vida está à mercê desse processo ininterrupto." "Assim como ciclos de vida e morte reconstroem o organismo e suas partes em conformidade com um plano, a cada momento o cérebro reconstrói o sentido do self." (DAMÁSIO, 2000, p.189) Associando o autismo e a depressão à perda de autoestima, o psicanalista Adam Phillips considera que preservar a sanidade envolveria, essencialmente, manter um self, "acreditar numa imagem, numa história ou num conjunto de fantasias preferidas - para amar." (PHILLIPS, 2005, p.120)

O psicólogo cognitivo Martin Conway reconhece nosso caráter multifacetado: "As representações do eu conceitual são esquemas e categorias socialmente construídos que definem o eu, os outros, e as interações típicas com os outros e com o mundo." (CONWAY, 2005, p.597) A experiência de alguém como um indivíduo requereria contínuas reativação e renovação dos enlaces dinâmicos de localização da identidade. Consideram Bruzzo e Vimal, "Se esses enlaces não forem periodicamente renovados eles são perdidos, com o risco de um descarrilhamento mórbido do senso de experiência." (BRUZZO e VIMAL, 2007, p.555) Condições psicopatológicas poderiam ser caracterizadas pela má administração dessa condição potencialmente assustadora de nosso eu. O paralelo entre estados patológicos e estados de flexibilidade cerebral é também considerado por Mendes, Carvalho e Wedeman (2004), que simularam processos de plasticidade neuronal em redes neurais auto-organizadas. São representadas condições supostamente associadas às formas de pensamento delirante, desorganizado e criativo, revelando o quanto pode ser frágil a fronteira entre estados considerados saudáveis e patológicos.

Seria a experiência do louco uma narrativa incompreensível para ou conflitante com as narrativas socialmente estabelecidas? Em um mundo todo ordenado e apoiado em verdades, regras e equações, a narrativa diferente, inédita, sempre corresponderá a conflito com 
narrativas estabelecidas. Reconhece Adam Phillips: "Trabalhar com pacientes esquizofrênicos pode tornar as pessoas entusiásticas com relação ao que os loucos podem dizer - muitas vezes não falando, ou não falando das maneiras usuais - que os supostamente sãos não querem ouvir." (PHILLIPS, 2005, p.113) Argumenta Foucault: "A história da loucura seria a história do Outro - daquilo que, para uma cultura é ao mesmo tempo interior e estranho, a ser portanto excluído (para conjurar-lhe o perigo interior), encerrando-o porém (para reduzir-Ihe a alteridade) (...)." (FOUCAULT, 1992, p.14) Conforme estudo sobre a implantação do alienismo no Brasil no início do século XX: "Os hospícios consolidam-se inicialmente como espaços destinados à cura, à regeneração e às tarefas de 'assistir, tratar e consolar' um tipo especial de enfermos da razão, incompatibilizados com as disciplinas requeridas pela ordem burguesa." (CUNHA, 1986, p.21)

\section{Outras narrativas}

Além da loucura, outras experiências nos oferecem narrativas alternativas que fogem à normalidade. Tal é o caso dos sonhos, das experiências paranormais e do efeito de drogas psicoativas. Essas experiências, tal como a loucura, podem se expressar em narrativas estranhas ao mundo bem comportado e controlado. A atividade no cérebro sonhante, nos termos de Krippner e Combs (2000), é menos "viscosa" que no cérebro em vigília, permitindo passear facilmente por padrões residuais deixados pelos humores e preocupações da vida desperta. Tal fluidez permitiria conexões mais fáceis entre sentimentos, recordações e produtos da imaginação. Em consequência, a experiência do sonho estaria aberta a mais novidades que a experiência desperta. 
Estados alterados de percepção são aceitos nos sonhos, onde, a princípio, não oferecem riscos. Já as chamadas substâncias entorpecentes são alvo de polêmica. Estas também oferecem narrativas alternativas, "estados alterados da consciência", mas são associadas a diversos graus de risco. O "drogado" é tido como um louco circunstancial ou temporário, como sugerido, por exemplo, na expressão "ficar doidão".

Outras situações que fogem ao controle das regras estabelecidas são as experiências paranormais, como a psicografia e a telepatia. A despeito da pouca predicabilidade das experiências com alucinógenos tipo LSD e da intangibilidade das experiências parapsicológicas, Krippner admite que as primeiras podem conduzir à ocorrência das últimas. Seguindo considerações de Albert Hofmann, Krippner sugere que em estados alterados sob LSD as fronteiras experienciais entre 0 self e o mundo tendem a desaparecer: "Uma parte do self avança no mundo exterior, nos objetos, que ganham vida, um outro e mais profundo significado." (KRIPPNER, 2006) Experiências de superação de fronteiras são também reconhecidos em "mirações" sob efeito de ayahuasca: "As imagens das mirações não são experienciadas dentro da cabeça, mas 'lá fora', no mundo astral, que é percebido dentro da mente do sujeito. $O$ dentro gera o fora, e os limites se tornam muito mais fluidos e flexíveis." (MERCANTE, 2006)

A segurança do conhecido, da normalidade, pode ser vista como um limitador, impondo limitações ao campo de possibilidades de narrativas? Superar fronteiras poderia então ser libertador. Admite Atlan que o imaginário em geral, desde suas derivações mitológicas às teorias "racionais" são ordenação na desordem. Estas ordenações, embora requeiram associações "livres" e criativas de memórias, não deixam de representar restrições, "uma vez que reduzem os graus de liberdade na exata medida em que associam." (ATLAN, 1992, p.176) Observam Bruzzo e Vimal sobre as tênues fronteiras que definem 0 
sujeito: "Ao lado de serem uma fonte de psicopatologias, as fronteiras abertas são um manancial de criatividade e até mesmo de um estado de consciência superior." (BRUZZO e VIMAL, 2007, p.560)

A rigor, do ponto de vista cognitivo, não haveria narrativas legítimas ou ilegítimas. Persistentes, nos recriamos continuamente, junto a uma representação de mundo. Nos vemos gravitando entre o nada e o tudo, criadores compulsórios, perpétuos mutantes, estados incessantemente alterados. 


\section{REFERÊNCIAS BIBLIOGRÁFICAS}

ATLAN, H. Entre o Cristal e a Fumaça. Ensaio Sobre a Organização do Ser Vivo. Rio de Janeiro: Zahar, 1992.

BRUZZO, A.A.; VIMAL, R.L.P. Self: an adaptive pressure arising from self-organization, chaotic dynamics, and neural darwinism. Journal of Integrative Neuroscience. Vol. 6, no 4, 541-566. Imperial College Press. 2007.

CONWAY, M.A. Memory and the self. Journal of Memory and Language. 53, p594-628, 2005.

CUNHA, M.C.P. O Espelho do Mundo - Juquery, a história de um asilo. Rio de Janeiro: Paz e Terra. 1986.

DAMÁSIO, A. O Mistério da Consciência - Do corpo e das emoções ao conhecimento de si. Companhia das Letras, 2000.

FOUCAULT, M. As palavras e as coisas. São Paulo: Martins Fontes, 1992.

HARRÉ, R.; GILLETT, G. A Mente Discursiva - Os Avanços na Ciência Cognitiva. Porto Alegre: Artmed., 1999.

HAUSER, M.D. Animal Minds. In: Science at the Edge:

Conversations with the Leading Scientific Thinkers of Today Edited by John Brockman , p83-102, 2008.

HERMANS, H.J.M.; KEMPEN, H.J.G. ; VAN LOON, R.J. The Dialogical Self - Beyond Individualism and Rationalism. American Psychologist. v.47, n.1 p.23-33. 1992.

KRIPPNER, S. LSD and Parapsychological Experiences. International Symposium on the Occasion of the 100th Birthday of Albert Hofmann, Suíça, 2006.

KRIPPNER, S.; COMBS, A. Self-organization in the dreaming brain. Journal of Mind and Behavior 21 (4):399-412, 2000.

MENDES, D.Q.; CARVALHO, L.A.V.; WEDEMANN, R.S. An Unifying Neuronal Model for Normal and Abnormal Thinking. Learning and Nonlinear Models. Revista da Sociedade Brasileira de Redes Neuronais, São Paulo, v. 3, p. 1-20, 2004. 
MERCANTE, M.S. - The Objectivity of Spiritual Experiences: Spontaneous Mental Imagery and the Spiritual Space. Revista Eletrônica Informação e Cognição, v.5, n.1, p.78-98, 2006.

PEZZULO, G. Coordinating with the Future: The Anticipatory Nature of Representation. Minds \& Machines. 18:179-225. 2008. 